Revista Electrónica Complutense de Investigación en Educación Musical ISSN-e: 1698-7454

http://dx.doi.org/10.5209/RECIEM.57179

\title{
Populismo y Educación Musical
}

\author{
Richard Colwell ${ }^{1}$
}

Recibido: 4 de febrero de 2017 / Aceptado: 5 de julio de 2017

Resumen. En este artículo el autor intenta bosquejar una respuesta a una cuestión planteada por los editores del British Journal of Music Education: qué se entiende por educación musical y qué experiencias deberían requerirse. El autor rechaza un análisis sobre los programas actuales ya que existe escaso consenso sobre qué tipo de programas tienen éxito. Examina la cuestión con una mirada más amplia e investiga sobre la influencia de los gobiernos en el modo en que respaldan la educación, sobre cómo son educados los docentes, y la importancia de la investigación relevante en el campo de las humanidades, desde una cultura nacional o global, o de los profesionales de la música. La educación musical es muy singular, y no está influida por el estado o por la preparación de los profesores. El currículo actual está influenciado, sin ninguna investigación, por profesores individuales que creen en la ciudadanía global en lugar de en la nacional. La historia de la cultura, un análisis de cómo los estudiantes responden a una obra de arte, y las ideas de un músico profesional intercultural con un compromiso con la educación tienen todas su base en la investigación cualitativa y pueden proporcionar una educación musical que tenga un significado importante y valioso.

Palabras clave: Populismo; educación musical; currículo; políticas educativas.

\section{[en] Populism and Music Education}

\begin{abstract}
In this article, the author attempts to frame a response to a question raised by the editors of The British Journal of Music Education: What is meant by music education and what experiences should be required. The author rejects an analysis or present programs as there is little consensus on successful programs. The author takes a step back and investigates the influence of the government that supports education, how teachers are education, relevant research in the arts, from a national or world culture, or from professionals in music. Music education is unique and not influenced by the state or the preparation of teachers. The present curriculum is influenced, without any research, by individual teachers who believe in world, rather than national citizenship. A history of culture, an analysis of how students respond to a work of art, and the ideas of a cross-cultural professional musician with a commitment to education do have a basis in qualitative research and can provide meaningful music education.
\end{abstract}

Keywords: Populism; music education; curriculum; educational policies.

Sumario: 1. Democracia. 1.2. ¿Por qué esta larga descripción de democracia? Dos ejemplos. 2. Investigación. 3. Educación. 4. Tres académicos han procurado llegar a un compromiso. 5. Educación y formación de docentes. 6. Cultura. 7 Música. 8. Referencias Bibliográficas.

Cómo citar: Colwell, R. (2017). Populismo y Educación Musical, en Revista Electrónica Complutense de Investigación en Educación Musical, 14, 75-93.

\footnotetext{
1 Universidad de Illinois toaster34@charter.net
} 
Los editores (Martin Fautley y Regina Murphy) del British Journal of Music Education escriben en su editorial de noviembre de 2016 que existe confusión no sólo sobre qué quiere decir educación musical, sino también sobre qué sucede y qué debería estar sucediendo en las clases etiquetadas como educación musical (p. 245). Se plantean además preguntas adicionales que incluyen qué es el pensamiento musical y qué es una actividad musical. Las preguntas de los autores sirven de inspiración para este trabajo de reflexión sobre cómo se buscan respuestas educadas e informadas a cuestiones tan profundas. Existen, por supuesto, múltiples cuestiones adicionales, como por ejemplo: “¿Qué es la comprensión musical?” y, “¿la educación musical sirve sólo como una herramienta para facilitar la consecución de valiosos objetivos educativos?". Quizás se enseña música para "enriquecer" la experiencia escolar como parte de una educación integral y completa. La prioridad educativa de la educación musical está relacionada con estas cuestiones. Las encuestas a padres de alumnos en los Estados Unidos revelan que la mayoría de los padres quieren música en las escuelas, pero cuando su prioridad se clasifica comparándola con la de otras asignaturas, aparece en último lugar (pero la asignatura que aparezca en último lugar puede aún resultar esencial si se evalúan los resultados). No parece existir un consenso sobre resultados valiosos para la enseñanza de la música o sobre el tiempo mínimo de instrucción que se requiere para obtener resultados relevantes para todos los ciudadanos, o incluso para los estudiantes con más interés y talento. Pero, ¿quién decide?, ¿y cuál es la verdad? La responsabilidad respecto a la educación musical es un problema al que se ha prestado atención desde hace tiempo, pero ¿cuál es el papel, si lo hay, del gobierno federal o estatal? A nivel local, parece que los maestros de aula tienen en muchos países la responsabilidad de proporcionar la instrucción de música que se exige, al menos en las escuelas primarias. Pero, ¿qué resultados se pueden esperar si el maestro tiene sólo un nivel de educación en música mínimo? En la educación musical británica, que originó las preguntas de Fautley y Murphy, el maestro generalista es el responsable de proporcionar la instrucción requerida. Los especialistas en música enseñan en las escuelas secundarias donde la música es una asignatura opcional, además de en los "núcleos educativos", que son esfuerzos conjuntos entre la comunidad (incluyendo los músicos profesionales locales) y las escuelas para ofrecer instrucción de música instrumental y coral, incluyendo orquestas. Tiene sentido que los maestros de aula sean responsables de todas las asignaturas requeridas, a menos que las estrategias de aprendizaje en la educación musical difieran sustancialmente de las estrategias de docencia en matemáticas y lengua. La Fundación Nacional para la Investigación Educativa en Gran Bretaña (NFER: National Foundation for Educational Research), respondió en octubre de 2016 a la investigación sobre educación primaria llevada a cabo por la comisión de estudios; concluyeron que si el propósito de la evaluación en primaria es el de la rendición de cuentas de la escuela, las pruebas nacionales obligatorias son el mejor método para juzgar el nivel de rendimiento de estas. Parece que la música no se considera una asignatura reglamentaria (p.4), así pues, no es de extrañar que haya confusión sobre la responsabilidad por los resultados de los estudiantes.

Los Estados Unidos tienden a emplear especialistas en música para la música requerida en las escuelas primarias. Estos diferentes planes didácticos -especialista frente a generalista- por país no deberían ser un factor a la hora de responder al desafío de Fautley-Murphy, a menos que haya una falta de acuerdo sobre el propósito de la educación musical en las escuelas. La literatura académica ha promovido una 
"música para todos". Es dudoso que esta creencia en una música para todos se mantenga ampliamente cuando los académicos están cuestionando actualmente qué nivel de matemáticas se requiere para todos. En los Estados Unidos incluso el propósito de la educación es objeto de debate. Según una encuesta de 2016 de Phi Delta Kappa, el $45 \%$ de la población cree que el propósito es el logro académico, pero sólo un tercio de los encuestados creen firmemente en ese propósito. "Ciudadanía" y "preparación para el mundo laboral" fueron las opciones elegidas por el $25 \%$ de los encuestados. E1 68\% por ciento preferirían que las escuelas se centraran más en habilidades técnicas/profesionales que en ofrecer más clases académicas avanzadas (NEA Today, 35 (3), 2017, p.11). Por lo tanto, cualquier discusión requiere la consideración de asignaturas optativas frente a las obligatorias y el papel de las ofertas de formación profesional frente a las académicas en las escuelas secundarias. La educación profesional se ofrece actualmente en cerca del $40 \%$ de las escuelas secundarias de la OCDE, con un porcentaje alto, del $70 \%$, en las escuelas checas y casi del $0 \%$ en los Estados Unidos.

2017 es una época de ira; una reacción, quizás, contra una clase dirigente e instituciones que han perdido el contacto con la realidad. La educación y la formación del profesorado son dos de estas instituciones y tal vez también la música. Los ciudadanos dudan de la capacidad de las "instituciones" gubernamentales, así como la de estos líderes en la democracia representativa, para llevar a cabo su percepción de la democracia del siglo XXI. Los movimientos de protesta, desde el de los indignados en España a los "occupy movements" en los Estados Unidos, buscan democratizar la democracia. En este artículo intento examinar las fuerzas y presiones sociales principales que podrían ayudar a esclarecer la situación y el fondo teórico para la educación musical, proporcionando así una base inicial para responder a las preguntas de Fautley-Murphy. John Dewey argumentó que las respuestas a la educación deben comenzar con lo que existe, y no con algún tipo de ideal. El punto de vista de Dewey complica el argumento. Los temas influyentes en el currículo parecen ser los siguientes: la democracia, las humanidades, la formación de docentes, la investigación y la música. Cada una de ellas trae consigo diferentes definiciones y prácticas.

\section{Democracia}

Hago la suposición de que la educación apoyada por el Estado debería realizarse con arreglo a las creencias democráticas de ese Estado. Es necesario además comparar la educación musical en un Estado democrático con la educación musical en Estados con otras formas de gobierno. Me centro en la democracia, puesto que la mayoría de los países en el mundo de hoy disfrutan de alguna forma de democracia, aunque el número esté disminuyendo; alrededor del 45\% de los países se consideran ahora "libres". Austin Sarat (2017) afirma que a la generación del milenio en los Estados Unidos le resulta indiferente vivir en una democracia, menos de un tercio de estos afirma que es esencial vivir en una democracia, en comparación con el 72\% de los nacidos antes de la Segunda Guerra Mundial. Jedediah Purdy (2017) afirma que "las encuestas recientes muestran que la mayoría de los estadounidenses menores de 30 años prefieren ahora el socialismo al capitalismo" $(i !)$. 
Actualmente se pueden dividir los argumentos sobre educación las democracias proporcionadas entre las dadas por los conservadores (nacionalismo) y por los progresistas, que piensan más en términos globales (Los países socialistas parecen estar más unidos). Los argumentos de ambosfuentes son complejos, con una amplia gama de puntos de vista dentro de cada uno. La educación es importante tanto para los conservadores como para los progresistas en todas las culturas y especialmente en las democracias. La elección y la libre discusión son dos elementos esenciales, pero estos dependen de quién define la libertad en educación y también de la libertad en los medios de comunicación. Acepto el término "populismo" para retratar ideas conservadoras, pero el populismo también existe en la izquierda. Un ejemplo de ello es un pequeño partido de España, "Podemos". Este partido se ha fusionado con el partido Izquierda Unida aprovechando la coyuntura de la crisis económica de España para oponerse al capitalismo global, las medidas de austeridad, el poder de la élite y la influencia de Alemania. Los populistas supuestamente representan el amplio sector de la clase media. Donald Trump ha obtenido gran éxito como candidato presidencial en los Estados Unidos debido a sus ideas populistas/conservadoras que se oponían a las ideas de las élites que han calado actualmente en la democracia americana. Andrew McCarthy (2017) afirma que "los populistas posnacionalistas de la izquierda buscan una gobernabilidad global más fuerte para controlar el comercio internacional, sin prestar atención al hecho persistente de que el Estado de bienestar, ya en una trayectoria de costo-beneficio insostenible, depende del crecimiento económico". Los populistas de la derecha ven la transferencia de la soberanía nacional a tribunales supranacionales, como la ONU, como un peligro al que hay que enfrentarse; quieren la evisceración de los arreglos multilaterales con la esperanza de que los beneficios del comercio se puedan acumular en el país, ignorando el hecho persistente de que el comercio internacional proporciona millones de empleos domésticos y reduce a la vez los costos de consumo" (McCarthy, 2017, p.6). Timothy Ash (2017) se pregunta si la definición de populismo no es sólo un vago término comodín que sirve para englobar partidos, movimientos y candidatos políticos que no nos gustan. Los populistas dicen hablar en nombre "del pueblo" y reclaman que la gente los legitima. El objetivo de estos populismos es la democracia liberal y los equilibrios constitucionales que supuestamente impiden cualquier restricción de los derechos individuales, protección para las minorías, tribunales independientes, una sociedad civil fuerte y medios de comunicación independientes y variados. Ash, como se puede deducir de su descripción de la diferencia entre el neoliberalismo y la globalización, cree que el populismo podría demoler los cimientos de una democracia liberal. El aumento del populismo puede ser un factor a tener en cuenta al definir cómo conseguir educar ciudadanos que sean democráticamente responsables. Los valores populistas son nacionalistas, y las prioridades gubernamentales/educativas difieren de las de un ciudadano global (progresista). Donald Trump ejemplifica los valores populistas, con vagas referencias a la educación. Los populistas desean un líder fuerte, un líder que crean que defiende sus valores. Los liberales pueden también valoran a un líder fuerte. A nivel universitario, el cuerpo docente a menudo prefiere dejar incluso decisiones importantes al decano o al rector, en lugar de tener reuniones y recoger datos que interfieran con el tiempo de que disponen para enseñar y actuar. La expectativa, tanto de los conservadores como de los progresistas, es que prevalecerán las reglas establecidas del juego. Los educadores musicales apoyan este populismo conservador cuando sus preocupaciones difieren de las del resto del 
cuerpo docente de las facultades de música. Para este cuerpo docente, la necesidad más urgente es probable que sea disponer de talleres y estudios completos. Los profesores universitarios son de forma abrumadoramente mayoritaria progresistas y votan al partido demócrata; esta es una de las inquietudes de la National Association of Scholars acerca del adoctrinamiento de los estudiantes por parte del cuerpo docente universitario. Justin Trudeau, primer ministro de Canadá (2016), afirma que la globalización no está funcionando para la gente común y expresa las ideas populistas menos extremas de Canadá. Para Trudeau, el auge del populismo se debe a sociedades divididas y a discursos del miedo. Presume de haber combinado los dos fines políticos, consiguiendo que Canadá esté abierto al comercio, la inmigración y la diversidad. Trudeau es también feminista, ha acogido refugiados sirios y apoya los derechos LGBT. Hay muchos populistas ultra-progresistas (Bernie Sanders, por ejemplo ) en las facultades de pedagogía que se oponen al estado actual de la democracia estadounidense, donde todas las disputas son juzgadas por indicadores económicos. Hay consenso en todas las democracias de que existen lagunas inaceptables no sólo a nivel económico, también en poder, educación, estatus e ideologías racionalistas, ya sea a la izquierda, a la derecha o al centro. Estas brechas no son nuevas, los investigadores han estado trabajando en ellas desde al menos desde la revolución industrial. El juez de la Corte Suprema, Louis Brandeis, que estuvo en servicio entre 1916 y 1939, argumentó que los Estados Unidos "podrían tener o democracia o riqueza concentrada en manos de unos pocos, pero no ambas. La igualdad política exigida por la democracia está siempre amenazada por la desigualdad económica y, cuanto más extrema es la desigualdad económica, mayor es la amenaza a la democracia" (Deaton, 2013, p.213). Desafortunadamente para este artículo, es difícil conectar democracia y educación, pues los académicos definen la democracia en términos amplios y generales. Peter Weibel (2014), en su obra "People, politics, and power" sugiere tres tipos de democracia: electoral, con votaciones libres y secretas; procedimental, que garantiza los derechos humanos y civiles; y maximalista, que sería el sistema de socialdemocracia que incluye el estado de bienestar. La relación del Estado con la educación es una disminución del nivel de democracia en la mayoría de los estados constitucionales; el descontento con la democracia está creciendo. El crecimiento del estado de bienestar ha disminuido el capital social, y la política pública está desplazada por la acción privada. Hay desigualdad, por definición, en las comunidades heterogéneas de las sociedades capitalistas democráticas. Sobre el argumento liberal democrático, es el Papa Francisco quien cree que la redistribución gubernamental de recursos es tanto legítima como necesaria, una acción que socava el capitalismo y está cercana a la teología de la liberación (2017, Whaples). En respuesta, los conservadores (populistas) sostienen que ningún país ha logrado nunca una prosperidad autosostenible a través de la redistribución del gobierno, ya que la redistribución fomenta la dependencia, el nepotismo y la corrupción gubernamental. La corrección política es un problema en la educación superior, como se mencionará más adelante. Las teorías políticas y educativas pueden ser funcionales, a la vez que conservadoras y liberales. La visión liberal, con énfasis en la autonomía individual, abogaría por contenidos y prácticas curriculares que cumplan con los estándares liberales de corrección política, pero la ésta es vista como un concepto elitista y ofensivo para los conservadores. El educador/filósofo Nel Noddings (2013) sugiere que las teorías funcionan para mantener el orden en la jerarquía de poder y privilegio. $\mathrm{La}$ democracia es estructura de poder incluso cuando el voto democrático es posible; 
pensemos en Turquía y su presidente Erdogan, o en Hungría y el Primer Ministro Orban. La democracia deliberativa basada en la democracia participativa puede deteriorarse hasta llegar al dominio emocional e ignorante de las masas irracionales (p.17). La globalización (progresista) ha sido promovida por las élites intelectuales, políticas y económicas. Las reformas a nivel mundial, los derechos de las mujeres, el medio ambiente, las minas terrestres, los derechos humanos, etc., han llevado a muchas élites a desarrollar identidades supranacionales y a restar importancia a sus identidades personales, de ahí el auge de la educación musical multicultural. La democracia se ha visto afectada por la globalización, el multiculturalismo, el cosmopolitismo, la inmigración, el subnacionalismo y el antinacionalismo y ha sacudido la conciencia nacionalista estadounidense. Las identidades étnicas, raciales y de género empezaron a adquirir relevancia tanto en la educación como en la sociedad. Los liberales temen que las estructuras educativas grandes y centralizadas, con un currículo común, puedan conducir a una burocracia que podría entonces perder de vista los objetivos de igualdad, derechos humanos y educación cívica.

\section{1. ¿Por qué esta larga descripción de democracia? Dos ejemplos.}

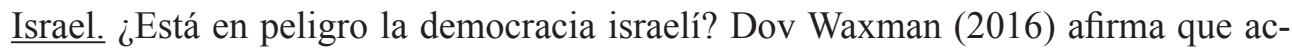
tualmente, la insistencia en la lealtad está configurando el currículo escolar en Israel. En diciembre de 2015 el ministerio de educación controlado por el partido nacional judío prohibió que la novela Borderline de la autora israelí Dorit Rabinyan fuera incluida en las clases de la escuela secundaria. El argumento de la novela incluye una historia de amor entre una mujer israelí y un hombre palestino. El Ministerio de Educación también reescribió el principal manual de educación cívica utilizado en las escuelas israelíes porque consideraban que algunos fragmentos eran demasiado críticos con el Estado.

Polonia. El gobierno de Polonia también ve la educación como un campo de entrenamiento para el nacionalismo polaco. El plan de estudios reduce el tiempo dedicado a las asignaturas de física, química, biología y tecnología de la información a favor del estudio de la historia, con sus héroes polacos y patrones patrióticos. Varsovia está siendo cuestionada por su oposición a las reformas educativas. Los sindicatos de maestros y el comité para la defensa de la democracia se están oponiendo al movimiento pro-nacionalista. El asunto que se discute es revocar una reforma de 1999 que abolió un sistema de dos etapas de escolarización que data de la era comunista. Actualmente hay 6 cursos en la escuela primaria, 3 más en la escuela media, y 3 o 4 cursos de escuela secundaria. (Neil Buckley y Evan Huber, 2017). Los gobiernos conservadores traen consigo su agenda, que pone el énfasis en la lengua y la cultura nativas, con todo su patrimonio nacional. Este enfoque corresponde a la "censura" en los Estados Unidos, cuando se prohíbe la presencia de conferenciantes conservadores y a veces progresistas, se retiran libros, y se "activan" avisos sobre su contenido.

Otros países ponen el acento en el nacionalismo para reducir la influencia musical externa. Pat Shand, en Canadá, ha supervisado durante mucho tiempo el proyecto Adaskin, que hace hincapié en el uso de la música canadiense en las escuelas. 


\section{Investigación}

Al argumentar la posición propia sobre el currículo, o sobre cualquier asunto básico para la educación general, la emoción y la pasión son a menudo más convincentes que la razón y los datos. Aarón Banks, en la presentación de un caso para el Brexit indicó que los hechos son ruido blanco; son las emociones las que nos dirigen. Por lo tanto, no se puede confiar en los datos para responder cuestiones obre el currículo de música. Con las elecciones de 2016 de EE.UU., se pueden citar cientos de ejemplos donde las creencias se han conformado debido a la persuasión de los oradores y contradiciendo los verdaderos hechos. Donald Trump, al atacar el plan Obamacare declaró que la renegociación de los precios de los medicamentos de Medicare ahorraría 300.000 millones de dólares al año, cuando Medicare gasta menos de la mitad de esa cantidad en medicamentos. Su administración se niega a declarar cuál es el nivel actual de desempleo de los Estados Unidos, lo que conduce a especular que esta negativa permitirá el uso de hechos "alternativos" para mostrar la mejora bajo la administración Trump. El público estadounidense nunca ha tenido los hechos en gran estima; tiene una desconfianza profundamente arraigada en el verdadero esfuerzo intelectual, probablemente porque los hechos destruyen los mitos sobre esos Estados Unidos que tanto amamos. Los investigadores han reconocido recientemente numerosas decisiones sesgadas basadas en ciencia inexacta, hasta el punto de que la Universidad de Virginia ha establecido un Centro de Ciencias Abiertas (Center for Open Sciences ). Este centro replica trabajos de investigación ya publicados. A fecha de escritura de este trabajo, sólo se han replicado 39 de 100 estudios y los estudios replicados mostraban sólo alrededor de la mitad del tamaño del efecto que figuraba en los estudios originales (se puede pensar que las decisiones sobre la educación musical basadas en estudios de casos no son ni replicables ni generalizables). La preocupación por la verdad me permite pasar de la investigación en la ciencia a la investigación en educación, ya que la formación del profesorado presenta los mismos problemas sobre uso de datos precisos. Kenneth Zeichner y Hilary Conklin (2016) sostienen que la investigación ha desvirtuado la formación de los docentes, y también las políticas y programas de programas de formación para profesores universitarios (su argumento es importante ya que las revistas que leen los docentes y los educadores de docentes son progresistas y muestran la existencia de importantes creencias [mitos] sobre la diversidad y la justicia social respecto a la educación). Zeichner y Conklin describen cómo unos planes de estudio muy limitados, que son realizados por encargo de un programa específico de formación del profesorado o por sus propios pequeños círculos de partidarios de ideas afines, son tenidos en cuenta como evidencia para la política respecto a la formación de docentes. La "política" resultante se difunde después de forma impresa y mediante las redes sociales y es aceptada en la formación de docentes. Una caja de resonancia (echo chamber), tal y como se define en los estudios de periodismo y medios de comunicación, es la amplificación y el refuerzo de las ideas por repetición, dentro de un sistema cerrado donde las opiniones diferentes o contrapuestas son censuradas o desautorizadas. $\mathrm{La}$ "política" resultante es entonces difundida por medios impresos y sociales y aceptada en la formación del profesorado. Los artículos en revistas de pedagogía se centran en gran medida sobre temas de diversidad y justicia social, apoyando el argumento de Zeichner y Conklin (2016) de que las cajas de resonancia son un problema importante para la profesión. La caja de resonancia, argumentan, se ha utilizado en la 
formulación de políticas educativas para documentar cómo una pequeña muestra no representativa de estudios se cita repetidamente para crear una situación oportuno en torno a una propuesta de política concreta. Pensemos, por ejemplo, en la proliferación de informes sobre la influencia de la música en la mejora en matemáticas. Estos informes-eco han tenido una enorme influencia en la formación de las políticas de educación de los maestros (ibíd.). El lenguaje que se incorpora a la reciente reautorización del ESEA, la Ley de Educación Primaria y Secundaria (Elementary and Secondary Education Act) promueve títulos de formación del profesorado en centros privados. La evaluación de los programas de formación del profesorado se basa principalmente en los comentarios de los estudiantes, y la validez de estos comentarios depende de cómo se formule la pregunta. Los datos de la investigación en educación suelen ser anecdóticos, cualitativos y estudios de casos. Los datos concretos y reales, claro está, como mediciones del rendimiento escolar y del nivel de pobreza, tampoco se asocian con la retención y/o el nivel de logro de los maestros. Una evaluación citada por Zeichner y Conklin (2016) es de un programa de formación de docentes que se centra en las estrategias de gestión del aula de Doug Lemov, Las cuales están basadas en las propias observaciones de Lemov y en conversaciones con individuos elegidos al azar (p. 17). Trump ganó las elecciones porque el público podía identificarse emocionalmente con sus ejemplos de inmigración, crecimiento lento, ideas liberales y políticamente correctas sobre educación, y la presencia de un "lodazal" en el gobierno federal. Existe caos en la educación cuando los estudiantes universitarios de hoy en día tienen dificultades para distinguir la verdad de la ficción. Tom Nichols, en un artículo (2017) sostiene que el fracaso en combatir la fantasía usando el razonamiento crítico está amenazando la estabilidad y el futuro de la democracia estadounidense. El Grupo de Educación de Historia de Stanford (Phi Delta Kappan, 2017) estudió a 7.800 estudiantes de 12 Estados y concluyó que la mayoría de ellos no tiene ni idea de cómo juzgar la credibilidad de las fuentes de noticias en línea. El estudio concluyó que existe la preocupación de que la democracia esté amenazada por la facilidad con que se permite que la desinformación sobre temas cívicos se difunda y prospere a través de las redes sociales y de otras fuentes donde la información no se revisa. La palabra del año en 2016 escogida por el Diccionario Oxford de lengua inglesa es "post-verdad", que define como "circunstancias en las que los hechos objetivos tienen menos influencia en la formación de la opinión pública que apela a la emoción y creencias personales". En los EE.UU., un alto porcentaje de la población no está seguro de cuál es la verdad del cambio climático, la evolución y el impacto del tabaquismo y las drogas.

\section{Educación}

Las escuelas existen para transmitir algo -creencias, conocimiento, actitudes, hábitos, etc.-. Las escuelas sirven a las sociedades y éstas dan forma a las escuelas, las cuales no existen fuera de la historia o la cultura. Las escuelas pueden transmitir una habilidad, pero estas habilidades pueden perder su valor para una sociedad donde no hay oportunidades para reflexionar sobre la cultura. Las escuelas enseñan la capacidad de entender y reflexionar sobre textos complicados que ofrecen una vía hacia el conocimiento de la historia y la tradición. En una democracia, los tribunales toman decisiones basadas en casos anteriores; así, el conocimiento de la historia 
daría lugar al gobierno de la ley. La obsesión por la diversidad multicultural antes que intercultural en nuestras escuelas y en la prensa ha producido una generación de progresistas narcisísticamente inconscientes de las condiciones ajenas a sus propios grupos autodefinidos e indiferentes a la tarea de llegar a los estadounidenses de todas las condiciones sociales (Lilla, 2016). Los movimientos políticos basados en la identidad parecen sumirse en rivalidades internas sobre quién es el más oprimido y quién debería tener prioridad. Estas categorías no explican lo que está pasando. El desafío principal no es cómo celebrar la diferencia. Es volver a recombinar una política de funcionamiento y modernizar la cohesión de una idea de Estados Unidos. Sentir una identidad de grupo es fundamental. El conservador Trump parece abogar por un enfoque hacia el nacionalismo basado en la pureza étnica. Para él, los programas humanitarios y políticamente correctos son inapropiados.

La formación de los maestros de música está controlada por las universidades de pedagogía; por lo tanto sus prioridades para las escuelas se convierten en metas educativas. Un ejemplo de la revista Harvard Education Review (Kuttner, 2016) sugiere que los educadores en humanidades en los centros de las ciudades quieren fomentar el pluralismo cultural como parte de un proyecto democrático de escuela, y como una necesidad para responder al cambio demográfico y social. Su argumento es que la pedagogía culturalmente sostenible puede conseguir perpetuar y fomentar el pluralismo lingüístico y cultural como parte del proyecto democrático de las escuelas. Noddings (2013) argumenta que democracia significa que todos los estudiantes deberían tener la oportunidad de prepararse para la universidad (¿y estudiar música?) si quieren hacerlo. Ser forzado a llevar a cabo estudios que no son de nuestro agrado puede que no constituya una oportunidad de aprender. Los educadores deberían ayudar a cada niño a descubrir en qué área tienen buenas habilidades, y qué les gusta saber y hacer. Esta filosofía apoya el movimiento actual de personalizar todo el aprendizaje. Diferentes estándares para diferentes estudiantes es la democracia deliberada que requiere de una perspectiva histórica en todas las disciplinas, incluida la música, para que la educación promueva un sentido crítico y juicios sólidos al servicio de la verdad y la justicia. En 2013 Tom Loveless concluyó que los estándares no importan mucho, y que poco han cambiado desde que fueron introducidos.

Las escuelas nos dicen quiénes somos y quiénes queremos ser. Hoy, el poder ha derivado en control. Las grandes cuestiones siguen ahí: ¿cuál es el significado de la vida, y cuál es la vida buena bajo un orden social específico?, ¿qué nos debemos los unos a los otros?, ¿qué podemos esperar?, ¿qué es lo mejor o qué es lo excelente? Estas preguntas se convierten en decisiones morales cuando se toma una decisión sobre la asignación de recursos. Las respuestas no se obtienen al referirse a la evidencia científica. Se usan factores subjetivos (cualitativos) de conciencia, juicio, práctica y elección. Ernest Boyer (2015) dijo que los educadores deberían enfatizar que existimos principalmente para servir al bien público. Sin embargo, los educadores de hoy se centran en la competencia individual (como en la composición musical, por ejemplo) en lugar de en las metas de la comunidad. 


\section{Tres académicos han procurado llegar a un compromiso}

Richard Haass cree que las ganancias liberales son demasiado valiosas para que el populismo las abandone, pero acepta que hay que hacer cambios para adaptar la democracia al siglo XXI. Haass (2017), presidente del Consejo de Relaciones Exteriores de los Estados Unidos, sugiere que el equilibrio de poder y el respeto a la soberanía que ha existido, tal vez, desde la Paz de Westfalia, ya no es suficiente. Su argumento se basa en lo que un país debe a otros países, una obligación soberana. No se está olvidando de los cambios requeridos en la educación por la percepción de que el nacionalismo es importante y de que los progresistas han ido demasiado lejos en no respetar las fronteras nacionales y no hacer más para atender las preocupaciones de todos los miembros de cada una de las naciones individuales del mundo. Las Naciones Unidas desempeñan funciones importantes, una de las cuáles es algo extrema: si un gobierno no cumple sus obligaciones para con sus propios ciudadanos, otras naciones pueden ejercer presión, incluida la intervención militar, para asegurar que se cumplan estas obligaciones, como quiera que se definan. Un ejemplo es el esfuerzo militar combinado de muchas naciones para liberar Kuwait después de que fuera invadido por Irak en 1990. Se podrían describir otros ejemplos pero no son esenciales para este artículo. Lo importante es el argumento de Haass de que la globalización está aquí para quedarse a pesar del autoritarismo resurgente en Rusia y China y del populismo en Europa y Estados Unidos. Los temas de salud, cambio climático, ciberespacio, derecho marítimo, terrorismo, proliferación nuclear, aranceles e incluso el rediseño de fronteras son problemas que sólo pueden resolverse mediante discusión y persuasión, apoyados por investigaciones de alto nivel. El acuerdo colectivo limitará las acciones de las naciones poderosas e incluso limitará el poder para hacer lo que sea óptimo para cualquier nación individual. La autonomía se sacrifica ahí donde la enfermedad debe ser erradicada o donde se debe llegar a un consenso sobre las responsabilidades. Los esfuerzos de Edward Said y Daniel Barenboim en apoyo de una orquesta Este-Oeste puede suponer un ejemplo de estos esfuerzos que demuestra la importancia de la música instrumental (¿y coral?) en la reducción de las tensiones que existen desde hace tiempo y contribuir en la reducción de las diferencias. Los objetivos del populismo son posibles, pero los asociados a la globalización reflejan un nuevo orden mundial. La rivalidad y la cooperación tendrán que ser parte del proceso. Al mismo tiempo que escribo esto, varias escuelas de Massachusetts están solicitando que las calificaciones individuales de sus estudiantes sean comparadas con las de estudiantes de Singapur y de otros países líderes. Es un hecho curioso que pocas escuelas, si es que las hay, estén interesadas en comparar los resultados de la educación musical. El público puede estar satisfecho de que el programa de música actual sea tan bueno como se dice que es. Sin embargo, los docentes de los Estados Unidos han adoptado con entusiasmo estrategias de enseñanza desarrolladas en Europa y Asia.

Thomas Friedman (2016) es también uno de los pocos optimistas cautos. Sus argumentos se centran más directamente en la educación al sugerir que la democracia actual sólo puede funcionar si los votantes saben cómo funciona el mundo, de modo que sean capaces de tomar decisiones políticas inteligentes y sean menos propensos a caer presa de demagogos, fanáticos ideológicos o amantes de las conspiraciones que puedan confundirles, en el mejor de los casos, o deliberadamente engañarles en el peor. El empoderamiento vendrá mediante el empoderamiento de la educación 
progresista y una nueva inmersión en la cultura, definida como una manera "correcta" de percibir, sentir, pensar y actuar. El control y la propiedad provienen de una educación amplia y completa y una combinación de habilidades técnicas e interpersonales. Uno se puede identificar con su referencia a Marie Curie, que dijo que "nada en la vida debe ser temido; sólo entendido" (p.3).

El comunitarista Amitai Etzioni (2017) sugiere que los progresistas deben intentar comprender a los populistas que votaron a Donald Trump. Los líderes progresistas necesitan mirar más allá de su superioridad moral y condescendencia. Etzioni cree que una comprensión de en qué consiste la comunidad puede servir de puente entre los globalistas que defienden los derechos individuales, la inmigración y el libre comercio, y los nacionalistas que anteponen su visión del país por encima de todo, que anhelan la vieja Norteamérica de comunidades cerradas, culturalmente y socialmente homogéneas (p. 22). La idea de que todos los ciudadanos tienen no sólo derechos, sino también responsabilidades, es una piedra angular del concepto de comunidad. Etzioni estaría sugiriendo que los populistas malinterpretan la globalización y su dependencia de relaciones fuertes, duraderas y significativas con los demás y de intercambio de valores morales y sociales. Los globalistas que abogan por el libre comercio y la inmigración ilimitada no aprecian la importancia de los lazos comunitarios que son esenciales para un sentido de identidad, estabilidad emocional y códigos morales. Los globalistas tendrán que aceptar que la asimilación migratoria exige que, para integrarse plenamente en un nuevo país, los inmigrantes abandonen sus culturas, valores, hábitos (música) y conexiones con su país de origen, manteniendo sólo los valores que son centrales para su identidad (¿podría esto incluir la música?). Los progresistas o globalistas cuya pasión por los derechos humanos e individuales debe comprometerse para entender los valores comunitarios. Para entender a aquellos individuos que votaron por Trump, los populistas necesitarán aceptar la diversidad dentro de un marco de unidad y valores compartidos en muchos tipos diferentes de comunidades. Los nacionalistas sienten la necesidad de proteger tanto la economía de su país como su identidad nacional. Se oponen a los derechos humanos en nombre del excepcionalismo nacional.

El filósofo inglés especializado en estética Roger Scruton (2017) también ha escrito sobre la división ocasionada por el populismo. Como conservador, cree en una progresión ordenada de la cultura. Sugiere que para que aliviar el problema del populismo, las cuestiones que se han planteado deberían convertirse en tema principal del debate público.

El excepcionalismo nacional ha sido utilizado en los Estados Unidos tanto por populistas como por globalistas (pensemos en Obama/Noddings) en la defensa de políticas y programas tales como las ideas de la Ilustración y la cultura nacional. Los defensores del libre comercio deberían aceptar la premisa de que llegar a acuerdos comerciales más justos con los trabajadores de un país es una demanda razonable y que los cambios surgen de los avances de la tecnología, no de las políticas comerciales. Trump opera sobre las emociones y la persuasión, mientras que sus acciones, y también las de los liberales, podrían reflejar un mejor razonamiento intelectual basado en el conocimiento de la historia y la cultura. El programa Musical Futures2 parece ser una actividad, no una experiencia con una base cultural sólida y con importantes características de tipo histórico. La profesora Green (2008) tiene razón al hacer hincapié

https://www.musicalfutures.org/ 
al considerar la escucha atenta como un instrumento de aprendizaje, aunque puede que haya puesto demasiado énfasis en su lo que dice sobre los músicos populares. Art Tatum, que es ciego, tuvo que aprender de oído. Wayne Shorter, Herbie Hancock, Bill Evans, Ornette Coleman, John Coltrane, Charles Mingus, Dizzy Gillespie, Thelonious Monk y, por supuesto, Wynton Marsalis, que se formó en Juilliard, recibieron todos una formación convencional. El Sistema venezolano se juzga desde múltiples perspectivas, tanto liberales como populistas. Un programa de música populista opcional basado únicamente en la composición en Gran Bretaña no ha tenido éxito en atraer a los estudiantes a realizar estudios adicionales de música.

Los compromisos políticos se basan en el poder de la globalización, con atención a la importancia de la cultura en materia de educación. La democracia es demasiado amplia como para dar respuestas a problemas preocupantes del currículo. El currículo de educación musical podría ser el mismo en países comunistas y en las democracias. Jia Xing Sie (2008) afirma que la música escolar debería ser responsable de establecer un concepto de música nacional y de fortalecer su patrimonio cultural. En el pasado, las canciones escolares habrían sufrido de demasiadas influencias norteamericanas y europeas. La música tradicional china fue criticada como parte del feudalismo. En la década de 1980, la educación musical china adoptó técnicas de composición del mundo occidental e importó música pop de Hong Kong, Taiwán, Estados Unidos y Europa. El movimiento nacionalista de hoy sugiere que puesto que China tiene una larga historia cultural de unos 8.000 años y múltiples grupos étnicos, esta música debe ser enseñada. El gobierno determinó que no había contradicción entre destacar la tradición musical y la diversidad musical en el mundo y que los valores culturales musicales chinos deberían enseñarse para cultivar la pasión de los estudiantes por la música china, así como su orgullo nacional y confianza en sí mismos. El programa de 1995 de apreciación de las humanidades en la escuela secundaria general señalaba que China es una nación con una cultura antigua y espléndida y que los profesores debían integrar cualidades ideológicas y artísticas en las canciones populares, las formas de arte popular, las arias de ópera y la música instrumental tradicional. Las escuelas locales podrían enseñar excelente música de otros países, de modo que constituyera un porcentaje menor del $20 \%$ del contenido curricular. La música contribuye a la identidad en los países comunistas del mismo modo que lo hace en los Estados Unidos con su posible orientación populista.

\section{Educación y formación de docentes}

Es de esperar que el apoyo a la educación musical por parte de los programas de formación de maestros no sea importante, ya que toda la atención en los contenidos seguirá centrándose en matemáticas y lenguaje. Una segunda inquietud es la crítica de las opiniones democráticas progresistas. La sección de Notas y Comentarios del New Criterion de enero de 2017 afirma que la educación superior es cada vez más hostil a la libertad de expresión, de investigación, de acción libre y en general a la formación de mentes libres. Los ejemplos captan las emociones de los populistas. La Universidad Estatal de Washington tiene un departamento de cultura crítica, de género y de estudios raciales. En el Estado de Washington no basta con exigir tolerancia o alentar el respeto hacia todas las opiniones; la escuela va a crear un cam- 
pus que afirme que es antirracista, anti-sexista, anti-xenofóbico, anti-homofóbico, anti-islamófobico, anti-discapacitados y anti-intolerancia, según el New Criterion. Peter Schmidt (2017) ha declarado que la enseñanza objetiva sobre la política en los Estados Unidos ha sido reemplazada y consiste ahora en alentar a los estudiantes a participar en activismo político de izquierdas. La asociación National Association of Scholars enumera los siguientes objetivos de educación superior de la administración Obama: la oposición al uso de combustibles fósiles; una masiva redistribución de la riqueza; intensificar el agravio por la identidad de grupo; restringir el libre mercado; expandir la burocracia gubernamental; elevar las normas internacionales por encima del derecho constitucional estadounidense; y despreciar nuestra historia e ideales comunes. Esta organización es especialmente crítica del aprendizaje en servicio (service learning), sobre el que argumentan que desvía la formación tradicional hacia la formación profesional. Uno de los ejemplos que citan tuvo lugar en la Universidad de Pensilvania, donde los estudiantes quitaron el retrato de Shakespeare y lo reemplazaron con una foto de Audre Lorade, una poetisa menor que se autodescribe como negra, lesbiana, madre, guerrera y poeta. El director del departamento de inglés (Lengua) defendió la acción declarando que los estudiantes estaban afirmando su compromiso con un propósito más inclusivo para el departamento de inglés. Los estudiantes pueden graduarse en las universidades estadounidenses sin un curso en la historia de la civilización occidental (Huntington, 2004). Algunas universidades exigen cursos sobre el tercer mundo o estudios étnicos, pero no cursos sobre civilización occidental. Una encuesta realizada en 1999 a estudiantes de los últimos cursos en las universidades más prestigiosas concluyó que el $90 \%$ de los estudiantes podía identificar a Rosa Parks, pero sólo el 25\% conocía la cita "el gobierno de la gente, por la gente y para la gente" del discurso de Gettysburg de Abraham Lincoln. A lo largo de la historia la educación ha sido fundamental para promover una identidad nacional. Ahora promueve la diversidad en lugar de la unidad y hace poco esfuerzo por inculcar a los inmigrantes la cultura, las tradiciones, las costumbres y las creencias norteamericanas (Huntington, 2004).

El mundo y la educación giran alrededor de la economía y el dinero, no los valores, la razón o la Ilustración. El objetivo se ha convertido en ganar y ser una nación de ganadores. Nel Noddings (2013) criticó a Barak Obama por su creencia de que Estados Unidos debe superar al resto del mundo en innovación, educación y construcción. Sugirió que esta era una manera de pensar del siglo XX, un hábito de pensamiento de dominación, de ser el número uno, y un celo evangélico para convertir al mundo a la democracia de estilo estadounidense. Obama y Trump, por lo tanto, aprecian el temor de la mayoría de los estadounidenses a ser relegados y no ser quienes consigan más medallas de oro olímpicas. Dejar de estar en cabeza a nivel mundial en la educación de los estudiantes en ciencia y tecnología supuestamente nos conduciría a ser una nación menos segura. Los drones, la guerra cibernética y otros artilugios secretos son necesarios para reducir el miedo al terrorismo y para demostrar que el gobierno tiene el control. Noddings (2013) sugiere que debemos renunciar a la búsqueda desesperada de la panacea universal y, en su lugar, preguntar respecto a cada idea sugerida: ¿Hay objeciones morales a ella? Si no las hay, ¿dónde podría ser útil?, ¿para quién?, ¿bajo qué condiciones? La extraña noción de que una forma de educación secundaria pueda preparar a todos los estudiantes para lo que viene después - la universidad o cualquier trabajo- es muy cuestionable; también es engañosamente antidemocrática, según esta autora. Noddings se pregunta igual- 
mente a qué propósitos sirven las actividades extracurriculares en nuestras escuelas secundarias. Los clubes y los grupos de rendimiento ofrecen oportunidades para que los estudiantes trabajen juntos, elijan responsables y establezcan metas y planes para la consecución de estas. No es una exageración afirmar que "las actividades extracurriculares saludables actúan como cuna de la democracia, un importante centro de prácticas para los ciudadanos jóvenes" (p. 22). Dorina Andrews, Gail Richmond y David Stroupe (2017), editores del Journal of Teacher Education, sugirieron que la campaña política en la democracia estadounidense trajo consigo una retórica que perpetuaba el racismo, el sexismo y una lista de fobias, y que la formación del profesorado de carácter universitario podría proporcionarles conocimientos en profundidad y las habilidades necesarias para incorporar una pedagogía orientada hacia la igualdad y un fundada en valores. El contenido de los cursos de formación de profesorado es la "educación", no la música, las matemáticas o la historia. Brewer, Xu y Diket (2017) abordan esta cuestión cuando hablan de una videoconferencia de Lee Shulman (2017) sobre el conocimiento del contenido pedagógico. Argumentan que los cursos para el profesorado de carácter educativo más general no proporcionan la plataforma de aprendizaje óptima para el conocimiento del contenido pedagógico y que esta base debería estar en el currículo, como la música o el arte. Este artículo contiene una sección sobre investigación que presenta el trabajo de Zeichner y Conklin (2016) con respecto a la mayoría de los temas que se encuentran en las revistas de pedagogía. Courtney Preston (2017) llevó a cabo lo que parece ser uno de los pocos estudios rigurosos sobre formación del profesorado. Investigó; con datos recogidos a lo largo de cinco años sobre 822 profesores de Carolina del Norte que utilizaban 15 diferentes programas universitarios, esta autora investigó el impacto de los cursos de psicología educativa en la formación de profesores, que se basan principalmente en la competencia en matemáticas y lengua y literatura, los dos cursos para los que los estados disponen de datos sobre estudiantes individuales. Encontró falta de rigor y relevancia, un currículo fragmentado, y falta de enfoque y atención a las necesidades de los adolescentes. Los trabajos de clase sobre el temario de la asignatura era el único tipo de tareas académicas (incluyendo la enseñanza de los estudiantes) asociado con logros en matemáticas, sin que hubiera ninguno asociado a lengua y literatura (p. 113).

\section{Cultura}

La música necesita el apoyo de las humanidades, la disciplina a la que pertenecen. Las artes liberales, bien entendidas, fomentan la libertad intelectual, la búsqueda de la verdad y la promoción de la ciudadanía virtuosa (Fish, 2017). El objetivo primordial de las artes liberales es cultivar el intelecto. William Deresiewicz (2015) defiende que las artes liberales y las humanidades son esenciales para llegar a ser plenamente humanos. Las artes liberales nos permiten crear sólidos argumentos basados en la evidencia, un razonamiento correcto, empatía e introspección, y se construyen sobre el estudio de la historia, la política y las artes. La inmersión en la historia del pensamiento y la gran literatura (incluida la literatura musical) fomenta el desarrollo de las virtudes intelectuales y, por lo tanto, del carácter. Debido a la enorme variación en las actitudes, los valores y las actividades humanas, no es posible especificar exactamente lo que en las 
artes liberales se debería aprender sólo por su propio valor intrínseco. La incapacidad de entender la importancia de las humanidades se traduce en que algunos estudiantes sean cultural y políticamente analfabetos cuando se gradúan de la universidad. Sin embargo, la importancia de las humanidades es un factor a considerar en la determinación de la importancia y prioridad de la música. Es interesante el hecho de que las academias militares de los Estados Unidos han mantenido los requisitos académicos en humanidades en la creencia de que facilitan la capacidad del candidato para pensar con amplitud de miras e incorporar la educación moral en sus decisiones. Las humanidades hacen que la vida tenga significado, ayudan a evitar el estancamiento intelectual y también el desaliento. La comprensión de la cultura requiere no sólo libertad de expresión, sino también de una mente abierta. Algunas universidades y escuelas públicas exigen activar un aviso ante cualquier idea que pudiera suponer una amenaza para el espacio de seguridad mental de los estudiantes, lo que se traduce en la prohibición de libros y obras de arte, y estos pueden ser cualquier obra que contradiga la visión del mundo de los estudiantes. Por lo tanto, las universidades no proporcionan a los estudiantes ninguna idea de la estructura del conocimiento, los temas que deberían aprender, o los libros y las habilidades que deberían dominar. Los estudiantes necesitan cursos más completos, especialmente en las artes y las humanidades, para poder construir una educación fundamentada.

\section{Música}

Las obras de arte no son divertidas; pueden ser difíciles, desafiantes e incluso provocativas, y no nos brindan su mensaje en un abrir y cerrar de ojos -que es lo que esperan los que buscan divertirse en las clases de música-. Lo que las artes están destinadas a proporcionar es seriedad, elevación, conocimiento y placer. El arte contemporáneo se entiende mejor en relación con el pasado, y es difícil conseguir esto cuando la música se promueve como un fin en sí mismo. El fin de las artes es atraer y conmover al espectador o al oyente. Un maestro es una clase de intelectual especial, a menudo educado y bien informado, cuya única función es organizar, difundir y modificar los objetos culturales, incluyendo la música, con el fin de persuadir a las masas de que Romeo y Julieta puede ser tan entretenido como West Side Story, y tal vez también educativo. Los graduados en Humanidades salen de la universidad con valores nuevos e interesantes. Las artes liberales deberían seguir estableciendo el estándar de lo que significa una educación universitaria. No se puede lograr educar para el pensamiento independiente y la participación activa en democracia sin las humanidades. La democracia requiere educación en humanidades, puesto que para comprender las fortalezas y debilidades de un país se requiere conocer la historia del nacionalismo y las responsabilidades globales. Éstas incluirían presumiblemente la influencia de la religión, el trabajo y el papel de las agencias gubernamentales. La educación proporciona el espacio "protegido" para explorar las palabras de Matthew Arnold (1969): "llegar a conocer, respecto a todos los asuntos que más nos preocupan, lo mejor que se ha pensado y dicho en el mundo y, mediante este conocimiento, traer una corriente de pensamiento libre y renovado sobre nuestras nociones y hábitos comunes que ahora seguimos de forma incondicional, pero mecánica". 
¿Existe un papel para la música en apoyo de la educación conservadora o liberal que, a su vez, apoye los objetivos de ciudadanía nacional o mundial? ¿Podría la música apoyar tanto a los gobiernos progresistas como a los conservadores, o es la educación musical un asunto importante sólo para subgrupos dentro de una democracia -asiático-americanos, afroamericanos o la clase media blanca-? Si hay un papel para la música, ¿cómo sería? No hay una respuesta directa, ya que las habilidades sociales (soft skills) que se pueden mejorar a través de la música son de alta prioridad para el público y los educadores; ciudadanía, cooperación, creatividad y, tal vez, una concepción de la música como un importante componente de las humanidades. Si la democracia, la investigación, la educación y la cultura tienen definiciones indefinidamente amplias, es necesario que se preste atención a aquellas asignaturas que proporcionan los elementos básicos para la construcción de la sociedad. Las cuestiones planteadas por Fautley y Murphy pueden responderse en una cultura populista. Si no, no es probable que la música esté a la cabeza en la lucha por los recursos, ya que las universidades y los programas de educación del profesorado minimizan el valor de la historia, la cultura y las humanidades. Los conservadores creen que la cultura occidental es valiosa y que merece apoyo en el campo de las humanidades y las artes, aunque la responsabilidad puede ser asignada al sector privado. En la actualidad, la educación musical, tal y como yo concibo la cuestión de Fautley-Murphy, no se limita al tiempo de clase, sino que puede definirse sólo teniendo en cuenta el apoyo privado y el comunitario. Las ideas, más que el capital, sostienen la educación musical actual. Es importante comprender esto si, como sugiere Dewey, los educadores de música necesitan comenzar con el presente, no con el ideal. Sin ciudadanía nacional, la ciudadanía global y la educación multicultural, incluida la música, serían inviables. Es difícil concebir que la música escolar tenga suficiente profundidad para su apropiada comprensión. Las lecciones privadas son importantes para instrumentistas y compositores. Las biografías mencionan con qué profesores estudiaron los músicos y su importancia es crítica para apreciar todos los tipos de música. Cualquier liderazgo de los Estados Unidos en el mundo respecto a la educación musical estaría en la excelencia de los conjuntos musicales. Japón y Australia han desarrollado grupos musicales escolares basados en modelos estadounidenses. Las escuelas de arte de referencia se centran en las actuaciones de los estudiantes, ejemplificado en la escuela de música Kaufman de la ciudad de Nueva York, donde los estudiantes también destacan en asignaturas académicas. Se le preguntó a la docente Tara Garcia Mathewson en Education Drive (17 de enero de 2017) cómo se puede agregar música a un plan de estudios. Su consejo: "Evitar cualquier programa de música que no permita que los niños actúen; la prioridad debería ser el gasto de recursos limitados en proporcionar a los niños la oportunidad de aprender un instrumento" (http://www. educationdrive.com/news/nycs-only-k-12-school-with-music-as-core-subject-seeshigh-outcomes/433960/). Sin embargo, Estados Unidos ha fracasado en la educación musical. Como Daniel Barenboim afirma, "la vida y la cultura de los conciertos están en peligro de deterioro a causa de los políticos que moldean las actitudes del público según lo que ellos elijan destacar" (https://www.nytimes.com/2017/01/22/ arts/music/review-bruckner-then-a-cultural-call-to-arms-at-carnegie-hall.html). No se puede poner la cultura al final de la lista. Argumenta que la música clásica no es elitista, ya que "la audiencia y los miembros de la orquesta pueden reunirse como una comunidad en un acto de comunicación humana y que los estadounidenses pueden unirse y engrandecer el mundo" (Tommasini, 2017, p. C6). Alexandra Wolfe 
(2017) escribe sobre la educación musical desde la perspectiva de Barenboim; Daniel Barenboim es un interlocutor entre la comunidad y la educación musical escolar, creando vínculos entre ellas. La música escolar pública en los Estados Unidos tiene programas cooperativos con organizaciones de música comunitaria y también se vale de artistas residentes en las escuelas. Barenboim ha recurrido a YouTube para publicar vídeos cortos de sí mismo tocando y hablando de varias obras para piano y de cómo de entender las grandes obras musicales. Este esfuerzo surgió de su inquietud al ver que el público no estaba siendo expuesto a suficiente música clásica. Atribuye esta deficiencia a la falta de educación musical para los jóvenes y su solución es involucrar a más "músicos" en la educación musical. Su análisis es que el problema no es ni económico ni social, sino una cuestión de prioridades educativas, como él enfatiza con una analogía: "Si no te enseñan el alfabeto, nunca leerás ningún libro" (Arthop, 2017). Su atención a la educación va más allá de enseñar al público la Sonata Claro de Luna de Beethoven, sino a un compromiso más amplio con el mundo, particularmente con el Medio Oriente. Supervisa una academia con sede en Berlín, la Barenboim-Said, que ofrece formación en música y humanidades para estudiantes de Oriente Medio y África del Norte. La academia recibe apoyo del gobierno alemán, lo que Wolfe considera importante. Barenboim afirma que "para mí la música tiene un aspecto humano y humanitario que es muy importante. La idea es que los estudiantes de música también deberían recibir clases de filosofía. Es muy necesario que los músicos aprendan a pensar en la música y con la música" (2017, entrevista con Shirley Apthorp, p.17). Roni Mann, director de una escuela de humanidades, dirige un plan de estudios que incluye una base filosófica, encuentros con la literatura de diferentes culturas, así como política, historia del mundo y ética. No es un currículo apolítico, pero permite dar cabida a discusiones sobre política desde un punto de vista que evita los habituales callejones sin salida de las identidades. Barenboim y Mann esperan que fomente la cooperación intercultural entre israelíes y árabes. Roni Mann es realista acerca de sus capacidades de pacificación: "La música no puede resolver conflictos", dice (http://www.west-eastern-divan.org/news/page/2/). Pero piensa que la música puede enseñar a las personas a trabajar juntas. La escuela es un ejemplo fantástico del poder de las personas para superar ciertas ideas... y cooperar. "Sangre judía fluye por mis venas, y mi corazón late por la causa palestina" (Wall Street Journal, 21-22 de enero de 2017, p.C11). A Barenboim también le preocupan los refugiados sirios: "Creo que los artistas e intelectuales no sólo tienen la posibilidad, sino también el deber, de hablar en contra de lo que consideran injusticias o actitudes equivocadas" (https://www.wsj.com/articles/barenboim-does-bruckner-at-carnegie-hall-1485298402). Cree que un día las cosas cambiarán. Barenboim es un importante educador e investigador en el campo de música e investigación cualitativa.

La Asociación Nacional de Educación Artística (National Art Education Association) obtuvo fondos sustanciales para analizar los resultados de la Evaluación Nacional en las Artes (Diket, Xu y Brewer, 2014). Estudiantes de 220 escuelas públicas y 30 escuelas privadas participaron en las pruebas, en las que se intentaba analizar el impacto del docente y la intensidad del estudio. Usando los datos de un bloque de la prueba, los investigadores pudieron identificar las ideas, conceptos y habilidades (constructos) que los estudiantes emplearon al responder. El conocimiento técnico era vital para desarrollar la comprensión estética y el significado estético (p. 22). Además, esto no podía enseñarse de forma independiente del conocimiento histórico y la conciencia crítica de las obras de arte contemporáneo. El acto de crear estaba 
asociado con el significado cuando la conexión era clara para los estudiantes. El resultado más revelador fue que el aprendizaje en un modelo con muchas aspiraciones pasa del conocimiento del arte al conocimiento técnico, y luego al conocimiento estético y finalmente al significado, de una manera secuencial (p.22). El conocimiento del arte se definió como información histórica, el conocimiento técnico se definió como las características formales, las propiedades estéticas como el estilo y el propósito, y el significado fue definido como la temática del contenido. Daniel Barenboim y Brewer, $\mathrm{Xu}$ y Diket son quienes han respondido a las cuestiones planteadas por Fautley y Murphy; la educación musical es, evidentemente, más que habilidad, trae consigo el bagaje de la filosofía, la historia, el significado y la cultura asociada. Existe un núcleo.

\section{Referencias Bibliográficas}

Andrews, D., Richmond, G., \& Stroupe, D. (2017). Editorial: Teacher education and teaching in the present political landscape: Promoting educational equity through critical inquiry and research. Journal of Teacher Education, 68(2), 121-124.

Apthorp, S. (2017). You dare not say no to Mr. Barenboim. Financial Times. Feb 25, p. 17.

Arnold, M. (1994). Culture and Anarchy (1969) New Haven: Yale University Press. In Lipman, S. (Ed.) The New Criterion, p. 5.

Ash, T. (2017). Is Europe disintegrating? New York Review of Books, LXIV, Jan 19, 24-26.

Boyer, E. (2016). Setting the Stage for a Leadership Framework. Transforming Professional Practice: A Framework for Effective Leadership, 1.

Brewer, T. Xu ,L. \& Diket, R. (2017). Confirming the significance of art specialists and aspirational learning. Art Education, 70(2), 16-24.

Buckley, N. \& Huber, E. (2017). Cultural counter-revolution hits Polish democracy. Financial Times, Jan 26, p. 3.

Deaton, A. (2013). The great escape: Health, wealth, and the origins of inequality. Princeton: Princeton University Press.

Deresiewicz W. (2015). Excellent sheep: The miseducation of The American elite and the way to a meaningful life, New York: Free Press.

Diket, R. Xu, L. \& Brewer, T. (2014). Toward and aspirational learning model: Gleaned from large-scale assessment. Studies in Art Education, 56(1) 397-411.

Etzioni, A. (2017). We must not be enemies. The American Scholar, Winter, 20-29.

Fautley, M \& Murphy, R. (2016). Editorial. British Journal of Music Education, 33(3), 245246.

Fish, S. (2017). Citizen formation is not our job. The Chronicle Review, Part B, Jan 27, p.13.

Friedman, T. (2016). Thank you for being late: An optimist's guide to thriving in the age of accelerations. New York: Farrar, Straus, and Giroux.

Green, L. (2008). Music, informal learning and the school: A new classroom pedagogy. Burlington, VT: Ashgate Publishing Company.

Haass. R. (2017). World order, 2.0. Foreign Affairs, 96(1), 2-9.

Huntington, S. (2004). Who are we? : The challenges to America's national identity. New York: Simon \& Schuster.

Kuttner, P. (2016). Hip-hop citizens: Arts-based, culturally sustaining civic engagement pedagogy. Harvard Educational Review, 86(1), 527-555. 
Lilla, M. (2016). The end of liberalism. New York Times, SR, Nov 18, p. 1.

Loveless, T. (2013). How well are American students learning? 2013 Brown Center Report on Education.

McCarthy, A. (2017). Populism versus populism. The New Criterion, 35(6), 4-13.

Mathewson, T. (2017). Music as a Core Subject. Education Drive, January 17.

NFER (2016). Education Select committee primary assessment inquiry. NFER Response, 28 October.

Nichols, T. (2017). Our graduates are rubes. Chronicle of Higher Education, January 15.

Noddings, N. (2013). Education and democracy in the $21^{\text {st }}$ century. New York: Teachers College Press.

Notes and Comments. (2017). The New Criterion, 35(5), 1-3.

Phi Delta Kappa. (2016). In NEA Today, 2017, 35(3), p. 11.

Phi Delta Kappan. (2017). Real confusion about fake news. February, 98(5), p. 6.

Preston, C. (2017). University-based teacher preparation and middle grades teacher effectiveness. Journal of Teacher Education, 68(1), 102-116.

Purdy, J. (2017). America's new opposition. New Republic, March, 26-31.

Sarat, A. (2017). The Guardian, Feb 11, p. 1.

Schmidt, P. (2017). Colleges are accused of using civics instruction to promote liberal activism. The Ticker in The Chronicle of Higher Education, January, 10.

Scruton, Roger. (2017). Representation \& the people. The New Criterion, 35(7), 4-11.

Tommasini, A. (2017). Bruckner, then a call to arms. New York Times C 6, January 23.

Trudeau, J. (2016). The Guardian, Dec 10.

Waxman, D. (2016). Is Israeli democracy in danger? Current History: A Journal of Contemporary World Affairs, 115(785), 360-362.

Weibel, P. (2014). People, politics, and power. In Weibel, P. (Ed.) Global activism: Art and conflict in the $21^{\text {st }}$ century. Karlsruhe: ZKM Center for Art and Media, 29-61.

Whaples, R. The economics of Pope Frances, An Introduction. The Independent Review, 21(3), 325-345.

Wolfe, A. (2017). Daniel Barenboim's mission for better music education. Wall Street Journal, Jan 21-22.

Xie, J. (2008). Inheritance of traditional music faced with globalization impact in schools of mainland China. In Leung, C. Yip, L. \& Imada, T. (Eds.). Music education policy and implementation: International perspectives. Hirosaki: Hirosaki University Press, 173-181.

Zeichner, K. \& Conklin, H. (2016). Beyond knowledge ventriloquism and echo chambers: Raising the quality of the debate in teacher education. Teachers College Record, 118(12), $1-38$. 